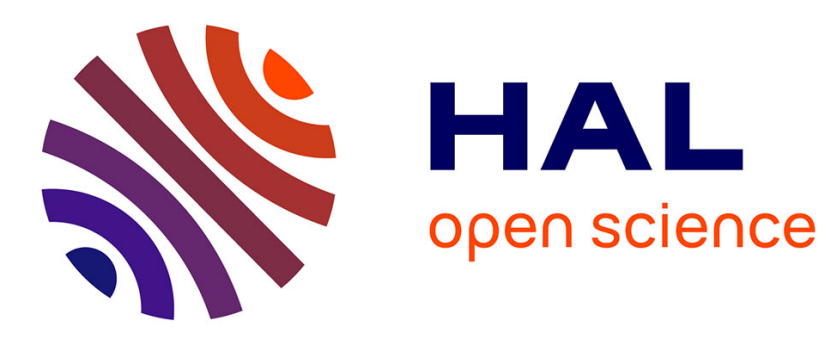

\title{
Statistical study of a large structural file based on the Mendeleev table
}

Michel Petitjean, Jacques Emile Dubois

\section{To cite this version:}

Michel Petitjean, Jacques Emile Dubois. Statistical study of a large structural file based on the Mendeleev table. Collection of Czechoslovak Chemical Communications, 1990, 55 (6), pp.1404-1415. 10.1135/cccc19901404 . hal-02123580

\section{HAL Id: hal-02123580 \\ https://hal.science/hal-02123580}

Submitted on 8 May 2019

HAL is a multi-disciplinary open access archive for the deposit and dissemination of scientific research documents, whether they are published or not. The documents may come from teaching and research institutions in France or abroad, or from public or private research centers.
L'archive ouverte pluridisciplinaire HAL, est destinée au dépôt et à la diffusion de documents scientifiques de niveau recherche, publiés ou non, émanant des établissements d'enseignement et de recherche français ou étrangers, des laboratoires publics ou privés. 


\section{4}

\section{STATISTCAL STUDY OF A YARGE STRUCTURAL FILE}

\section{BASED ON THE MENDELEEV TABL}

\section{Michel Perriten and Jacques Emile Dubors}

ITODYS (Institut de Topologie et de Dynamique des Systemes),

Received July 31,1989 Accepted November 7, 1989

Dedicated to Professor Otto Exner on the occasion of his 65th birtldday.

The atom or element content of a large structural n̂le is considered through relations between the occurrentes of the elements and their geometric dinsidered as a rectangular $(7 \times 32)$ con" tingency table. The porential of various geometric tools is explored with different CAS files.

The chemical knowledge inherent in large structural files is difficult to apprehend. The chemical knowledge inherent in large stly with precision. The simplest informaThe number of parameters increases drastically with precil defined classification. This tion contained in a file is the atom, element of a well defined clasts of data. We highly generic parameter allows simple handing of large amounts of data. We explore a method which is an alternative and a complement to the univariate analysis consisting of the list of atoms and their occurrences, where the element positions in the Mendeleev table is omitted. Considering the type of input data, no new interpretation may be expected, the interest rather lies in pointing out classical features differently and in establishing a basis for futher possible investigation. Elemental composition statistics coming from the CAS file in 1967, 1974, 1979 and 1987 were published, giving the statistical weights of the elements. In this paper, a large CAS subnile available at the ITODYS and containing $3424428 \mathrm{com}-$ pounds registered up to July 1978 is investigated (incompletely defined structures and coordination compounds were not taken into account in order to preserve homogeneity of handing and use). The distribution of each of the 103 elements has been considered.

The the carbon distribution (mean 16.985, standard deviation 9.56) without carbon are not included here).

The hydrogen distribution also offers a greater set of even values which may be explained by the abundance and the odd valency of hydrogen (according to graph

\begin{tabular}{|c|c|c|c|c|c|c|c|}
\hline \multicolumn{8}{|c|}{ Large Structural Fije } \\
\hline \multicolumn{8}{|c|}{$\begin{array}{l}\text { TAale I } \\
\text { The carbon distribution in the } 3424428 \text { CAS compound file }\end{array}$} \\
\hline Atom & Compounds & Atom & Compounds & Atom & Compounds & Atom & Compo \\
\hline 1 & 7866 & 43 & 4204 & 85 & $14 \hat{z}$ & 127 & 25 \\
\hline 2 & 15103 & 44 & 5362 & 86 & 183 & 128 & 29 \\
\hline 3 & 20660 & 45 & 3690 & 87 & 135 & 129 & 36 \\
\hline 4 & 37579 & 46 & 4112 & 88 & 217 & 130 & 36 \\
\hline 5 & 47194 & 47 & 2495 & 89 & 127 & $13 !$ & 37 \\
\hline 6 & 84992 & 48 & 4069 & 90 & 199 & 132 & 51 \\
\hline 7 & 93749 & 49 & 1973 & 91 & 125 & 133 & 34 \\
\hline$s$ & 129229 & 50 & 2756 & 92 & 121 & 134 & 50 \\
\hline 9 & 146038 & 51 & 1787 & 93 & 118 & 135 & 30 \\
\hline 10 & 187807 & 52 & 2244 & 94 & 106 & 136 & 59 \\
\hline 11 & 175058 & 53 & 1372 & 95 & 121 & 137 & 40 \\
\hline 12 & 202276 & 54 & 2145 & 96 & 176 & 138 & $3 i$ \\
\hline 13 & 181448 & 55. & 1344 & 97 & 107 & 139 & 38 \\
\hline 14 & 197990 & 56 & 1664 & 98 & 144 & 140 & 36 \\
\hline 15 & 184784 & 57 & 1208 & 99 & 121 & 141 & 29 \\
\hline 16 & 187214 & 58 & 1285 & 100 & 122 & 142 & 50 \\
\hline $\begin{array}{l}16 \\
17\end{array}$ & 157197 & 59 & 783 & 101 & 89 & 143 & 31 \\
\hline $\begin{array}{l}17 \\
18\end{array}$ & 159743 & 60 & 1407 & 102 & 98 & 144 & 47 \\
\hline 19 & 135080 & 61 & 727 & 303 & 68 & 145 & 31 \\
\hline 20 & 140901 & 62 & 1002 & 104 & 83 & 146 & 29 \\
\hline 21 & 120291 & 63 & 752 & 105 & 63 & 147 & 29 \\
\hline $2 z$ & 111367 & 64 & 911 & 106 & 73 & 148 & 36 \\
\hline 23 & 85749 & 65 & 604 & 107 & 56 & 149 & 23 \\
\hline 24 & 82790 & 66 & 793 & 108 & 111 & 150 & 43 \\
\hline 25 & 59191 & 67 & 395 & 109 & 58 & 151 & 40 \\
\hline 26 & 57846 & 68 & 682 & 110 & 72 & 152 & 23 \\
\hline 27 & 47725 & 69 & 440 & 111 & 60 & 153 & 28 \\
\hline 28 & 45445 & 70 & 567 & 112 & 51 & 154 & 36 \\
\hline 29 & 32856 & 71 & 315 & 113 & 49 & 155 & 21 \\
\hline 30 & 36803 & 72 & 704 & 114 & 67 & 156 & 18 \\
\hline 31 & 22545 & 73 & 300 & 115 & 46 & 157 & is \\
\hline 32 & 24253 & 74 & 330 & 116 & 47 & 158 & 20 \\
\hline 33 & 16332 & 75 & 289 & 117 & 55 & 159 & 23 \\
\hline 34 & 18537 & 76 & 436 & 118 & 46 & 160 & 14 \\
\hline 35 & 11373 & 77 & 234 & 119 & 36 & 161 & 9 \\
\hline 36 & 14993 & 78 & 370 & 120 & 68 & 162 & 11 \\
\hline 37 & 8459 & 79 & 208 & 121 & 41 & 163 & 10 \\
\hline 38 & 9759 & 80 & 344 & 122 & 45 & 164 & 12 \\
\hline 39 & 6548 & 81 & 244 & 123 & 39 & 165 & 6 \\
\hline 40 & 8958 & 82 & 267 & 124 & 43 & 166 & 4 \\
\hline $\begin{array}{l}40 \\
41\end{array}$ & $\begin{array}{l}5260 \\
520\end{array}$ & 83 & 140 & 125 & 41 & $\begin{array}{l}167 \\
167\end{array}$ & 3 \\
\hline 42 & 7534 & 84 & 280 & 126 & 37 & $16 \$$ & 11 \\
\hline
\end{tabular}

Collest, Czech, Chem, Commun. Nol, 55$)$ (19s0) 
TABLE

(Continued)

\begin{tabular}{|c|c|c|c|c|c|c|c|}
\hline Atom & Compounds & Atom & Compounds & Atom & Compounds & Atom & Compounds \\
\hline 169 & 8 & 176 & 2 & 183 & 3 & 196 & 2 \\
\hline 170 & 8 & 177 & 6 & 185 & 1 & 198 & 1 \\
\hline 171 & 3 & 178 & 3 & 187 & 1 & 199 & 1 \\
\hline 172 & 2 & 179 & 1 & 188 & 1 & 200 & $i$ \\
\hline 173 & 7 & 180 & 6 & 189 & 3 & 206 & 1 \\
\hline 174 & 1 & 181 & 3 & 190 & 3 & 208 & 1 \\
\hline 175 & 4 & 182 & 1 & 191 & i & 220 & 1 \\
\hline
\end{tabular}

theory, there is an even number of odd-connected nodes). The distribution of many data registered in the file has also been obtained: bonds, components, valencies, charges, isotopes, and other data depending or not on the recording mode of a compound.

When the total number of each element is obtained we suggest a statistical view Whe from the most to the Ienst abundant. Either alphanumeric or graphic presentations

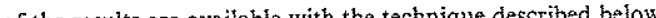

\section{METHODS AND RESULTS}

Performing Correspondence Analysis

We show here the results of relations carried out on the most elementary level of chemical knowledge, that of the atom. The methodological tools issued from correspondence analysis are used in this paper for the first time in this feld.

Corron analysis are used in this paper for the frst Correspondence analysis is a multivariate exploratory technique devated to conts) This technique is similar to PCA (principal component analysis), but applied to categorical data; the contingency table is the Mendeleev table, described with two categorical variables (see Tables II and III): the period of the element ( 7 categories), and the chemical family ( 32 categories). This rectangular formatting of the periodic table is conventionally obtained by assigning a zero value to non-pertinent position (this 2D-presentation shows the occurrences as a potential third dimension).

Compared to $\mathrm{PCA}$, the contingency table may be considered as a set of 32 indiviCols described with 7 continuous variables, or a set of 7 individuals described with 32 continuous variables; both $\mathrm{PCA}$ (individuals are weighed, and variables are ( Then eigenvalues and vectors

\section{Large Structural File}

are computed (Table IV). The highest eigenvalue is 1 for every contingency there are only $7-1=6$ factorial axes. Each of the 148815839 atoms of now has its 6-dimensional coordinates, but the coordinates of the atoms ba ame saine 103 elements of the Mendeles

TABLEI

Oceurrence of the elements in the Mendeleev table

\begin{tabular}{|c|c|c|c|c|c|}
\hline $\mathrm{H}$ & 70908654 & $\mathrm{Kr}$ & 200 & Lu & 366 \\
\hline $\mathrm{He}$ & 51 & $\mathrm{Rb}$ & 1338 & $\mathrm{Hf}$ & 375 \\
\hline $\mathrm{Li}$ & 7668 & $\mathrm{Sr}$ & 1138 & Ta & 628 \\
\hline $\mathrm{Be}$ & 654 & $Y^{\prime}$ & 626 & w & 1746 \\
\hline B & 66864 & $\mathrm{Zr}$ & 1219 & $\mathrm{Re}$ & 585 \\
\hline c & 57528231 & $\mathrm{Nb}$ & 577 & Os & 333 \\
\hline $\mathrm{N}$ & 5820786 & Mo & 2295 & Ir & 265 \\
\hline 0 & $10 \$ 68323$ & $\mathrm{Tc}_{\mathrm{c}}$ & 234 & Pt & 542 \\
\hline$F$ & 767626 & $\mathrm{Ru}$ & 435 & $\mathrm{Au}$ & 443 \\
\hline $\mathrm{Ne}$ & 70 & $\mathrm{Rh}$ & 397 & $\mathrm{Hg}$ & 9047 \\
\hline $\mathrm{Na}$ & 48281 & $\mathrm{Pd}$ & $\begin{array}{r}557 \\
2441\end{array}$ & $\mathrm{Ml}$ & $\begin{array}{r}1796 \\
37477\end{array}$ \\
\hline $\begin{array}{l}\mathrm{Mg} \\
\mathrm{Al}\end{array}$ & $\begin{array}{l}4522 \\
4773\end{array}$ & $\begin{array}{l}\mathrm{Ag} \\
\mathrm{Cd}\end{array}$ & $\begin{array}{l}\begin{array}{l}4441 \\
1587\end{array}\end{array}$ & $\mathrm{Bi}$ & $\begin{array}{l}3477 \\
1094\end{array}$ \\
\hline $\begin{array}{l}\mathrm{Al} \\
\mathrm{Si}\end{array}$ & $\begin{array}{r}4773 \\
124453\end{array}$ & In & 625 & Po & 162 \\
\hline p & 233598 & $\mathrm{Sn}$ & 17823 & At & 156 \\
\hline s & 1101733 & So & 4214 & $R_{n}$ & 73 \\
\hline $\mathrm{Cl}$ & 1110863 & $\mathrm{Te}$ & 3050 & $\mathrm{Fr}$ & 79 \\
\hline Ar & & I & 94361 & $\mathrm{Ra}$ & 108 \\
\hline K & 14964 & $\mathrm{Xe}$ & 317 & $\mathrm{Ac}^{\mathrm{A}}$ & 84 \\
\hline $\mathrm{Ca}$ & 4649 & $\mathrm{Cs}$ & 1711 & $\begin{array}{l}\text { Th } \\
\mathrm{Pa}\end{array}$ & $\begin{array}{l}659 \\
156\end{array}$ \\
\hline $\begin{array}{l}S c \\
\text { Si }\end{array}$ & $\begin{array}{r}480 \\
2739\end{array}$ & $\begin{array}{l}\mathrm{Ba} \\
\mathrm{La}\end{array}$ & $\begin{array}{r}2971 \\
907\end{array}$ & $\mathrm{U}$ & $\begin{array}{r}156 \\
1230\end{array}$ \\
\hline $\mathrm{v}$ & 1816 & $\mathrm{Ce}$ & $\$ 12$ & $N p$ & 302 \\
\hline $\mathrm{Cr}$ & 2625 & $p_{r}$ & 669 & $p u$ & 321 \\
\hline $\mathrm{Mn}$ & 1649 & $\mathrm{Nd}$ & 776 & Am & 221 \\
\hline $\mathrm{Fe}$ & 5661 & $\mathrm{Pmi}_{\mathrm{m}}$ & 118 & $\mathrm{~cm}$ & 113 \\
\hline $\mathrm{Co}$ & 2681 & $\mathrm{Sm}$ & 751 & ${ }^{B k}$ & 90 \\
\hline $\mathrm{Ni}$ & 2444 & $E_{u}$ & 596 & $\mathrm{Cf}$ & 98 \\
\hline $\mathrm{Cu}$ & 3934 & Gd & 584 & Es & 83 \\
\hline $\begin{array}{l}\mathrm{Zn} \\
\mathrm{Ga}\end{array}$ & $\begin{array}{l}3827 \\
708\end{array}$ & $\begin{array}{l}\text { Tb } \\
\text { Dy }\end{array}$ & 504 & $\mathrm{Ma}$ & $\begin{array}{l}12 \\
56\end{array}$ \\
\hline $\mathrm{Ge}$ & 8895 & Ho & 397 & No & 61 \\
\hline As & 12560 & $\mathrm{Er}$ & 530 & $\mathrm{Lr}$ & 51 \\
\hline Se & $\begin{array}{r}20508 \\
507\end{array}$ & $\mathrm{Tm}$ & 340 & & \\
\hline $\mathrm{Br}$ & 257583 & $Y b$ & 499 & & \\
\hline
\end{tabular}

Coct. Crech. Chem. Commun. (No1. 55) (1998) 
The projection of the points in the first factorial planes is given in Fig. 1 ; it is possible, just as for PCA, to interpret the factorial axes. The first axis shows an opposition between most and least abundant elements, and the second shows an opposition between low and high atomic numbers: the actinides group and the lanthanides group are far from other elements. The geometrical repartition of these 103 points is a picture of the statistical content of the Mendeleev table, suitable for points is a picher followion

TABLE YII

The coningencey table: the 7 rows and 32 columns are exchanged for clarity

\begin{tabular}{|c|c|c|c|c|c|c|}
\hline 51 & 70 & 86 & 200 & 317 & 73 & - \\
\hline- & 767626 & 1110863 & 257583 & 94361 & 156 & - \\
\hline - & 10568323 & 1101733 & 20508 & 3050 & 162 & - \\
\hline - & 5820786 & 233598 & 12560 & 4214 & 1094 & \\
\hline .- & 57528231 & 124453 & 8895 & 17823 & 3477 & - \\
\hline- & 66864 & 4773 & 708 & 625 & 1796 & - \\
\hline- & - & - & 3827 & 1587 & 9047 & - \\
\hline$\ldots$ & - & - & 3934 & 2441 & 443 & - \\
\hline - & - & - & 2444 & 557 & $\$ 42$ & - \\
\hline - & - & - & 2681 & 397 & 265 & - \\
\hline - & - & - & 5661 & 435 & 333 & - \\
\hline - & - & - & 1649 & 234 & 585 & \\
\hline - & - & - & 2625 & 2295 & 1746 & - \\
\hline - & - & - & 1816 & 577 & 628 & - \\
\hline$=$ & - & - & 2739 & 1219 & 375 & - \\
\hline - & - & - & - & - & 366 & $5 l$ \\
\hline - & - & - & - & - & 499 & 61 \\
\hline- & - & - & - & - & 340 & 56 \\
\hline - & - & - & - & - & 530 & 12 \\
\hline - & - & - & - & - & 397 & 83 \\
\hline & - & - & - & - & 504 & 98 \\
\hline- & - & - & - & - & 409 & 90 \\
\hline - & - & - & - & - & 584 & 113 \\
\hline - & - & - & - & - & 596 & 221 \\
\hline - & - & - & - & - & 751 & 321 \\
\hline - & - & - & - & - & 118 & 302 \\
\hline - & - & - & - & - & 776 & 1230 \\
\hline- & - & - & - & - & 669 & 156 \\
\hline- & - & - & - & - & 812 & 659 \\
\hline - & - & - & 480 & 626 & 907 & 84 \\
\hline - & 654 & 4522 & 4649 & 1138 & 2971 & 109 \\
\hline 70908654 & 7668 & 48287 & 14964 & 1338 & 1711 & 78 \\
\hline
\end{tabular}

Collect. Cxech. Chem. Commun. Nol, 55) (1990)

\section{Large Structural File}

Convex Hulls and Peeling

It is difficult to provide a simple description of a 6-dimensional set of without altering information. For a one-dimensional set, a possible descrip the ordering of the points, pointing out the extremal values; for a multidime

TABLE TV

Igenvalues and inerria percen

\begin{tabular}{cc}
\hline $\begin{array}{c}\text { Eigenvalues } \\
\text { (except trivial value 1) }\end{array}$ & $\begin{array}{c}\text { Associated cumulated } \\
\text { inertia percent }\end{array}$ \\
\hline 0.998074 & $45.054 \%$ \\
0.586131 & $71.512 \%$ \\
0.364415 & $87.962 \%$ \\
0.218656 & $97.833 \%$ \\
0.041272 & $99.696 \%$ \\
0.006742 & $100-000 \%$ \\
\hline
\end{tabular}

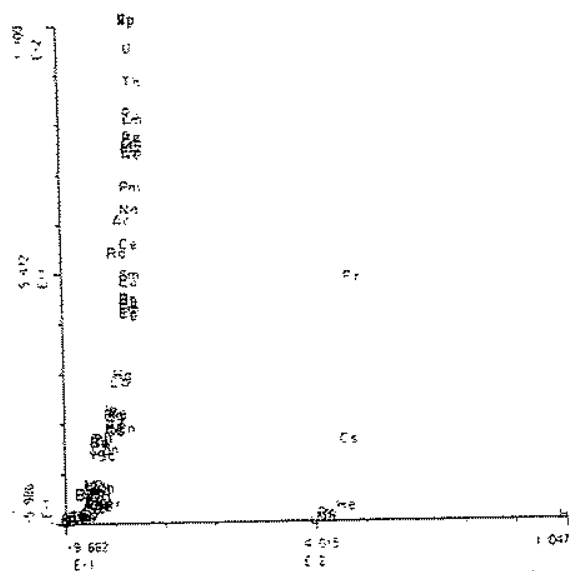

FIG. 1

The 103 atomic symbols in the first factorial plane (axis 3 vertical, axis 2 horizontal)

Colicat, Crech, Chem Commun. (Nol. 55) (1990) 
set, it is also possible to give extremal values and a partial ordering. Extremal values are, mothematically speaking the extremal points of the convex hull of the set. The con the convex sets containin the poins it is atso the smatlest polyhedron containing the points. The vertices of this polyh is an alled the extremal points. This polyhedral hull offers a simple description of the shape of the set.

After the convex hull has been computed, the set of the internal points is consiAfter the convex hull has been computed, the set of the first one; we then consider dered. This new set also has a convex hull, enclosed no the fining points. This process, the new internal points, and so on, until there are no remaining points. This process describing the wide set.

When the points are projected on a sub-space, it is known that the convex hull of the projections is also the projection of the convex hull. Thus every bidimensional of the pull computed in a factorial plane can provide a display of the projection of the mutidimensional convex bull (however, the peeling of the bidimensional set ho mot extremal points may be on none of the factorial planes).

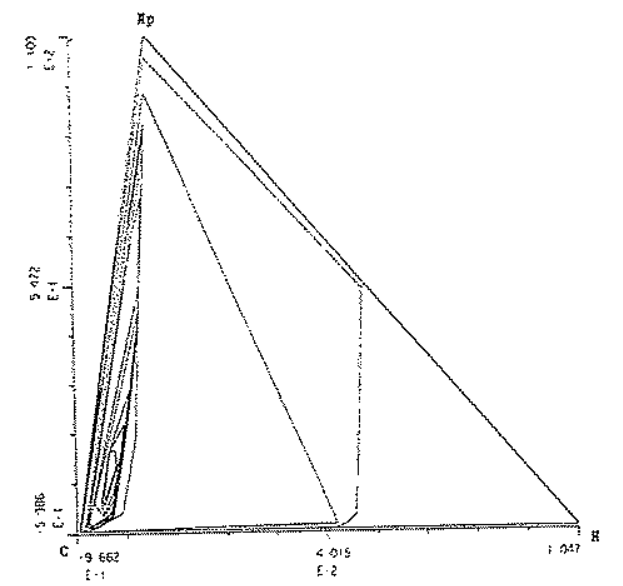

Fio. 2

Peeling of the 103 atomic symbols in the first factorial plane (axis I vertical, axis 2 horizontal)

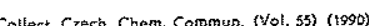

\section{Large Structural File}

The peeing in the first factorial plane is shown in Fig. 2; extremal points first factorial plane are ordered trigonometrically (Table V). Since all the 148 atoms of the file take only the 103 positions of the elements in the factoria the convex hull of the 103 elements is also the convex hull of the 148815839 We point out that the peeling of the 148815839 atoms (and not of their 1 tions) provides a different set of successive convex hulls, together with an 0 of the 103 symbols. The least abundant on the external hull is the first syn moved by the algorithm; then the new least abundant on the external hull is re moved by the algor he the reme and so on until no elment remans. This propoth wain in the dure for data analysis, requires a special algorthm saning much computatio The example below comes from the first ractorial plane (see Table $V$ and A compound is a geometric mean of its atoms (a geometric mean is a linear combination), and every one of the 103 thiatomic conpounds exist file. Thus, the external convex bull or the 103 elements is also the convex hul 3424428 compounds. The extremal compounds are those monoatomic com whose unique atom is extremal, such as $\mathrm{C}, \mathrm{H}$, or $\mathrm{Np}$.

Comparison with Other CAS Files

The elemental composition statistics published ${ }^{1}$ give reference data to be $c 0$ with the 1978 file. The 1974, 1979 and 1987 files, and the file defined by $d:$

TABLE $\mathrm{V}$

Peeling in the first factorial plane

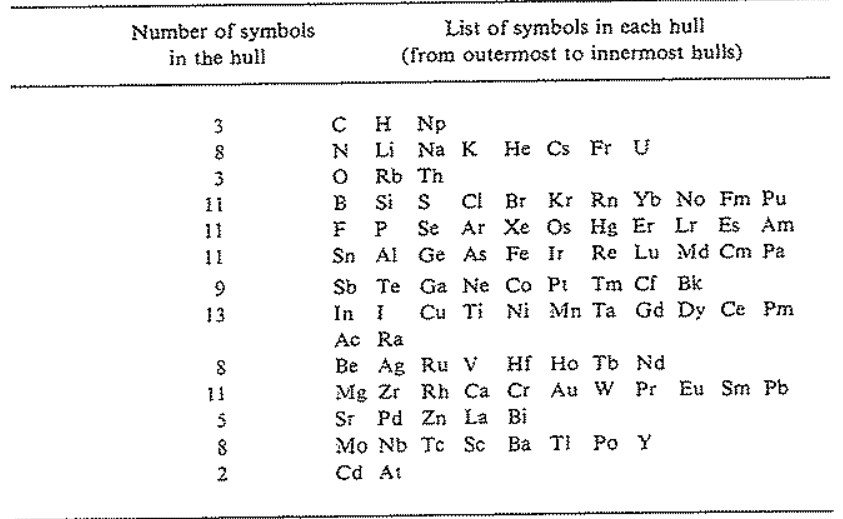

Collect. Crech. Chem. Commun. (Nol. 55) (1990)

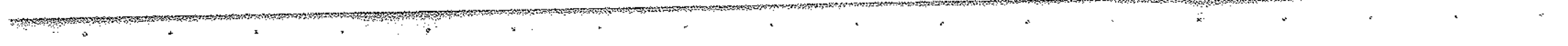


between 1987 and 1979 data, were treated with correspondence anaiysis (the 1967 file was not considered because many elements were missing: see ref. ${ }^{\prime}$. The $c 0$ ordinates of the symbols gave similar shapes for successive hulls, either with or without weighed symbols (see e.g. Fig. 4).

We show the infuence of a perturbation starting from a probable printing error for the occurrence of W in the CAS 1974's file (see Table VII). The value 134149 is then improbable, and does not match with the value computed with the percentage: $23768 \mathrm{~W}$ atoms. The cumulated sum of all the elements computed with the data also given in ref. ${ }^{1}$ is then 118283553 , which leads to $23790 \mathrm{~W}$ atoms.

The data sets, differing only by the number of $W$ atoms, are compared; the varia* The dat sets dimensionl coordinates of W are shown in Table VII. The relative tions of the 6 dimensional cooding war are

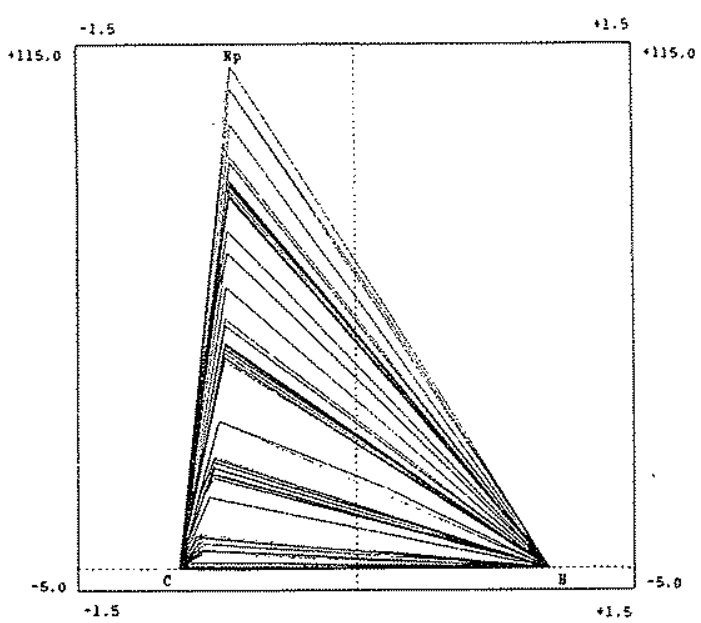

Peeling of the 148815839 atoms in the first factorial plane (axis 1 vertical, axis 2 horizontal)

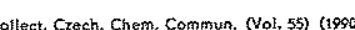

\section{Large Structural File}

\section{TABLE VI}

Peeling of the weighed symbols in the first factorial plane

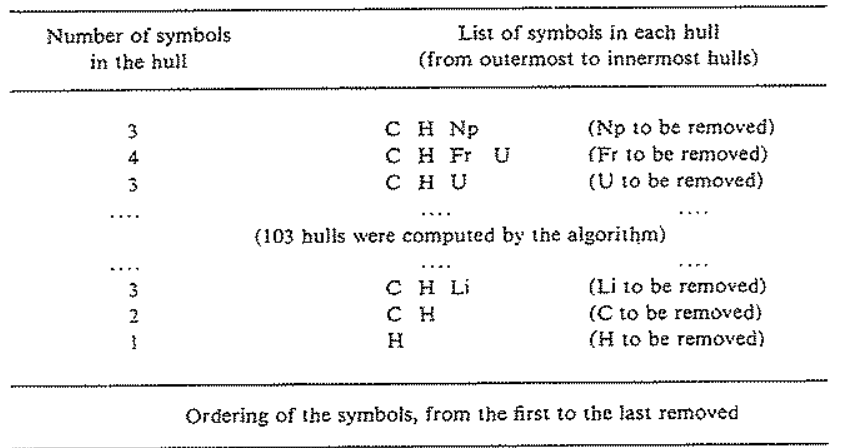

$\mathrm{Np}, \mathrm{Fr}, \mathrm{U}, \mathrm{Th}, \mathrm{Pu}, \mathrm{Am}, \mathrm{Pa}, \mathrm{Bk}, \mathrm{Es}, \mathrm{Cf}, \mathrm{Cm}, \mathrm{Md}, \mathrm{Lr}, \mathrm{Fm}, \mathrm{No}, \mathrm{Ac}, \mathrm{Pm}, \mathrm{Ra}, \mathrm{Nd}, \mathrm{Ce}, \mathrm{Sr}$ Tb, Ho, Dy, Gd, Tm. Lu, Er, Yb, La, Cs, Hg, W, Tl, Re, Pb, Bi, Ba, Po, Ta, Y, At, Pt

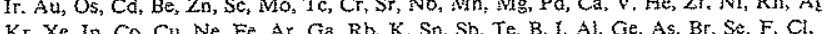

$\tau_{A B L E}$ VII

Infiuence of a perturbation on the coordinates

1974 fie: $134149 \mathrm{~W}$ atoms $(0.020113 \%$ of the 118173172 atoms $)$ 1979 fie: 44549 W atoms $(0.022214 \%$ of the 300537175 atoms) 1987 file: 88739 W atoms (0.022481\% of the 394730177 atoms)

\begin{tabular}{|c|c|c|c|}
\hline Axis & $134149 \mathrm{~W}$ atoms & $23790 \mathrm{~W}$ aloms & $23768 \mathrm{w}$ at \\
\hline 1 & $-0.7714984 E \div 60$ & $-0.7732 \mathrm{CCOE} \div-00$ & $-0.7732018 \mathrm{E}$ \\
\hline 2 & $0.1366503 \mathrm{E} \div 02$ & $0.1117546 E \div 02$ & $0.1117443 \mathrm{E}$ \\
\hline 3 & $-0.3353852 \mathrm{E} \div 01$ & $-0.4478106 E \div 01$ & $\begin{array}{l}-0.4478546 \mathrm{E} \\
-0.673183 \mathrm{~F}\end{array}$ \\
\hline 4 & $-0.7318581 \mathrm{E}+01$ & $-0.6753468 E \div 01$ & $-0.6752183 \mathrm{E}$ \\
\hline 5 & $-0.1906342 E \div 01$ & $-0.3382746 \mathrm{E}+01$ & $-0.3381835 \mathrm{E}$ \\
\hline 6 & $-0.3689612 E \div 00$ & $0.8848312 E \div 60$ & $0.8861454 E$ \\
\hline
\end{tabular}

Collest. Crech. Chem. Commun. Nol, 1 (s) (1990) 
DISCUSSION AND CONCLUSION

This attempt to present a multivariate analysis of a large structural file shows how simple graphic displays may give characteristic pictures of the file intended for comparison with others. The information taken from the file was limited to atomic nature, giving a graphic representation of the Mendeleev table. A complete interpretation of the graphic Mendeleev table and its ordering of the symbols with peeling would require a 6-dimensional algorithm, numerically consolidated. Only 2-dimensiona examples were presented, in order to bave simple outputs and results. The technique can be easily extended to all information registered in the file (and not only to atomic nature), using multiple correspondence analysis.

No problem was encountered in handling large amounts of data. Every contingency table can be computed with an execution time proportional to the number f individuals, without using storage areas (except for the contingency table itself which is small compared to the large number of individuals). Every computation needed for simple or multiple correspondence analysis can then be performed without rereading the file.

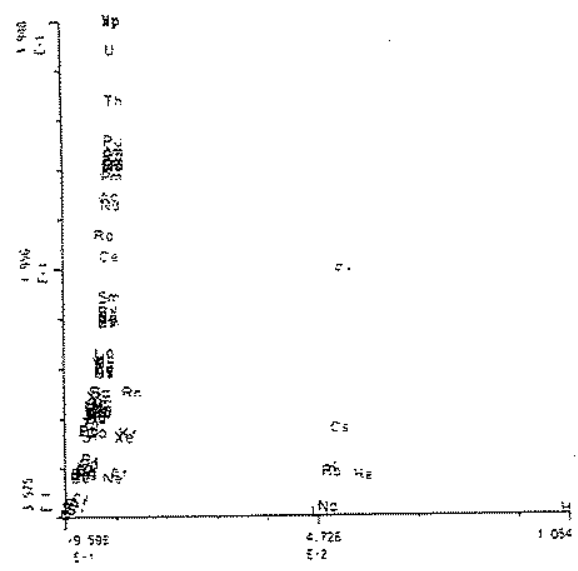

The 103 atomic symbols in the first factorial plane (CAS 1987) (axis 1 vertical, axis 2 horizontal)

\section{Latge Structural File}

It is also possible to define the 6 -dimensional coordinates of each of the 3 compounds. A compound is a group of atoms, each atom having one of 6.dimensional coordinates. A correct representation of the compound will geometric mean of its atoms (this is a ustal definition of groups in correspc analysis); for example, every uniatomic compound will take the coordinate unique element. Moreover, there is a distance between every couple of cam unique tement so thit a chemical synthesis can be repre for correlation attempts or class unarbitrary nut algorithms.

The coordinates obtained here for compounds having the same element position are identical, but a multiple correspondence analysis performed with describing expanded formulas will give separate points. This approach is each time a set of categorical variabies is defined over a file, followed by correspondence analysis. When structural descriptions of compounds are nec QSAR or related correlation and classification problems, the problem is us convert these descriptions into continuous values, which are required fo analyses. This problem can be replaced by a new one: how to define a set of cat yariables to obtain a good representation of structural information. This n blem is easier to solve, because structural information has indeed a qualitative (e.g. fragments, chemical family, functional group), and not a numerical multiple correspondence analysis can then be performed to give the expecter nuous values.

\section{REFERENCES}

Stobaugh R. E.: 3. Chem. Inf. Comput. Sci. 28,180 (1988).

2. Benzecri 3. P.: L'analyse des données, Tome 2: ISBN 2-04-007225-X of 2-04-007335-3. Paris 1973.

3. Greenacre M., Hastie T.: J. Am. Stat. Assoc. 82, 437 (1987).

4. Barnett V., Y. R. Stat. Soc., A. 139, $318(1976)$.

6. Holnesich 